\title{
El convento clariano de la Concepción de Mérida: paradigma de fundación pía no autónoma
}

\author{
M. ${ }^{a}$ Elisa Martínez de Vega *
}

Desde que se fundase a comienzos de 1228 el monasterio de Santa Engracia, primer monasterio de monjas clarisas en España, el impulso fundacional no se detuvo en el trascurso de los siglos XIII-XIV y XV. Durante el siglo XVI, la Contrarreforma y la explosión de la religiosidad en la Península se dejan sentir a través de 83 nuevas fundaciones. El Seiscientos significa una ligera recesión en el ritmo de crecimiento, con un total de 66 fundaciones clarianas, antes de asistir a la crisis de la siguiente centuria en la que tan sólo se fundan siete nuevos conventos de religiosas de Santa Clara.

La fundación del convento de la Concepción de Mérida, cuyo estudio abordamos en las próximas líneas, ocurre a caballo entre dos siglos: el de la eclosión clariana en España y la Edad del Barroco, centuria proclive a la piedad y al fervor religioso, promovidos por el aliciente y espíritu tridentino que tanto arraigó en la sociedad española del siglo XVII.

\section{LA FUNDACIÓN DEL CONVENTO DE LA CONCEPCIÓN DE MÉRIDA: RASGOS Y SEMBLANZA}

La fundación del convento de Mérida es un ejemplo singular de fundaciones que se promueven por individuos sin descendencia. Existe una tendencia similar en las fundaciones de la pequeña nobleza, muchas de las cuales fueron llevadas a cabo por matrimonios sin hijos o mujeres célibes '. En este caso, el matrimonio formado por Lope Sánchez de Triana

Universidad Complutense. Madrid.

Véase el estudio de Miura AndRades, J. M., Las fundaciones de la orden de Predicadores en el reino de Córdoba. (I), AD, IX, 1988. 
y Catalina Medina, los fundadores, pertenece a la oligarquía local de Mérida, con un nivel económico elevado. Así, es la ausencia de herederos lo que les induce a canalizar un buen número de rentas y propiedades a este tipo de actividades. Además, con ello y mediante la figura del patronato vinculado a personas de linajes colaterales, se obtendría una proyección en el tiempo de la propia persona simbolizada en su obra.

La iniciativas fundadoras desde fines del siglo XVI se presentaban, sobre todo, en los miembros de familias vinculados a la Corona por el desempeño de oficios o por actuaciones bélicas determinadas. En estas acciones, que eran un reflejo de la consolidación de la posición socioeconómica de los fundadores, hemos de valorar la asimilación de pautas de conducta y expresión de prestigio propias de los grupos sociales de superior extracción y posición en la jerarquía social. Estamos ante la famosa difusión por simpatía de pautas de conducta de la alta nobleza que tienden a ser imitadas por los grupos sociales inferiores, como ya expusiera Georges Duby ${ }^{2}$.

Lope Sánchez de Triana puede ser un claro ejemplo de este sentido imitativo. Perteneciente a la oligarquía local, desempeña la profesión de la medicina, con el grado de doctor, mas su elevada posición económica lo motiva para tratar de emular a la alta aristrocacia guerrera, consiguiendo como ella lo había hecho en los siglos precedentes, prestigio y fama a través de la fundación de un convento, de religiosas de la Orden de Santa Clara.

Este proceso imitativo parece arraigar con más precocidad en las oligarquias urbanas que en las oligarquías propiamente aldeanas o rurales. Paralelamente, en los últimos decenios del siglo xvi se produce una corriente migratoria conventual; no deja de ser significativo que diversas comunidades religiosas emigren a las ciudades o a la capital, la villa por antonomasia, al amparo de lo urbano ${ }^{3}$. Las clarisas, por su parte, comprendieron o les hicieron comprender, que en la sustitución de sus moradas aldeanas por otros emplazamientos urbanos radicaba buena parte de su éxito, al incardinarse en la dinámica expansiva de las ciudades en el siglo xvi. Con el cambio era previsible que participaran de los bienes que los linajes urbanos canalizaban en este tipo de instituciones, al tiempo que se situaban en el epicentro social de reclutación de nuevos efectivos humanos que engrosaran sus filas ${ }^{4}$.

DuBY, G.: Guerriers et paysans. Paris Gallimard 1973.

3 Véase al efecto el estudio de Martínez Vega, M. E. y Marín Bafriguete, F., «La difusión de las clarisas descalzas: la fundación del convento de San Pascual Bailon de Madridm, Congreso Las Clarisas en España y Portugal. Salamanca 1993.

4 MuÑoz Fernández, A., "Fundaciones conventuales femeninas en el ámbito rural madrileño 
Del convento clariano de Mérida se conservan dos escrituras de fundación. La primera corresponde al año 1592, pero el 19 de julio de 1602, en virtud de una cláusula de reservación, los fundadores, ante el escribano público de la ciudad de Mérida, Pedro Sánchez Moreno, modificaron la primera fundación con el objetivo de aumentar la renta de las capellanías adscritas al monasterio y de introducir ligeras variaciones en las cláusulas de gobierno del convento. Contaron para ello con el beneplácito de Diego de Perada, prior de la provincia de León y del Consejo Real.

\section{INDIVIDUO, LINAJE Y GRUPO SOCIAL COMO BENEFICIARIOS}

El origen del convento de la Concepción de Mérida en la provincia de Badajoz aparece explícitamente ligado a la noción de linaje y vinculado a la estrategia de un patriciado urbano, no ya en ascenso sino en vías de consolidación.

En su proceso fundacional, en sus cláusulas, símbolos materiales y figuras jurídicas desencadenadas como el patronato, encontramos la más clara muestra de esta vinculación. El ilustre linaje del patronímico Sánchez en Extremadura tuvo un solar raíz en Alburquerque de donde salieron muy eminentes varones. A él pertenece el fundador del convento de la Concepción, el doctor Lope Sánchez Triana, quien, conjuntamente a su esposa, Catalina de Medina, vecinos ambos de la "muy noble y muy antigua ciudad de Mérida" fundó y dotó convenientemente el monasterio mencionado.

Podemos preguntarnos cuáles eran las motivaciones y los fines encomendados a la casa fundacional. El documento argumenta, en primer lugar, el deseo, la posibilidad y la obligación cristiana de la adopción espiritual de los hijos de Dios al

«no haber sido Dios servido de conceder esta merced de hijos naturales y procurar por otros medios adquirillos, adoptándolos o dejando en sus memorias y haciendas a los que bien quieren y, como el espíritu con tan grandes ventajas se adelanta a la carne, las personas a quien la bondad de Dios hizo aquella de los criar en medio de la sana y santa doctrina de su madre la Iglesia Católica Apostólica Romana por adopción de hijos de Dios que se hace en el sacramento del Bautismo. Reagradeciendo esta merced, están obligados a la servir con todas sus fuerzas y caudal considerando estos $y$ otras grandes e infinitas mercedes que de

(siglos XV-XVI, Actas del / Congreso Internacional del Monacato Femenino en España, Portugaly América, 1492-1992.T. II. León 1992, págs. 477-499. 
la mano de Dios sin merecimiento nuestro hemos recibido y cada día recibimos" 5 .

Con esta actitud los fundadores muestran su evidente agradecimiento a Dios

«por habernos dado bienes y hacienda en abundancia naturales a quienes la pusiésemos y debiésemos dexar por lo cual damos a su Magestad divina infinitas gracias, queriendo con mucho contento que en nosotros se cumpla la divina voluntad con la prontitud, obediencia y alegría que en cielo se cumple" ${ }^{6}$.

La fundación, en segundo lugar, quedaba vinculada al grupo social, en este caso, y por extensión, a toda la ciudad de Mérida, mediante la figura institucional del patronato, tal y como consta en los prolegómenos fundacionales:

“Nosotros el doctor Lope Sáncez de Triana y Doña Catalina de Medina, su muger, vecinos de esta muy noble y muy antigua ciudad de Mérida, pretendiendo volver a Dios lo que nos ha dado y servirle con ello y justamente ilustrar y adornar nuestra patria y naturaleza que es esta ciudad de Mérida y aprovechar nuestros deudos, parientes y amigos, disponiéndolo de manera que todos hayan parte de nuestros bienes y hacienda, así los presentes como los por venir, siguiendo ellos el camino de la virtud y religión después de haber encomendado a Dios Nuestro Señor esta obra que más propia y verdaderamente es suya, que la disponga, enderece y acabe como más convenga a la gloria de su Altísimo nombrem $^{7}$

La tercera pretensión de los fundadores insiste en la remisión de los pecados y provecho de las almas propias. Así mismo se reservan el derecho en sus personas a ser enterrados en la iglesia del convento y a levantar un sepulcro al efecto en la parte y lugar que se señalare en su día, aunque, debido a los graves inconvenientes que se derivaban de esta costumbre se prohibe taxativamente tal práctica a los sucesores en el patronazgo, bajo pena de privación de todos los derechos sucesorios acordados en el documento de fundación y dotación ${ }^{8}$.

${ }^{5}$ Escritura de Fundación del Convento de la Concepción de Mérida (Badajoz). AHN Clero. Libro 994, f. ${ }^{\circ} 1$.

Ibidem.

7 Ibidem, f. ${ }^{\circ} \mathrm{Iv}$.

- Ibidem, f. ${ }^{\circ} \mathrm{vv}$. Cláusula decimocuarta. Se trata de una modificación de la escritura original ya que en esta los patronos se reservaban el derecho a adjudicar enterramientos, arcos y capillas en la parte de la Iglesia que se señalare al efecto. 
Por último, estamos - dadas las especiales circunstancias del matrimonio cofundador, más concretamente la ausencia de hijos legítimos-, ante un prototipo de vinculación de la fundación al linaje a través del nexo de unión que proporciona la figura institucional del patronato.

Se entrelazan, pues, en una trama compacta, motivaciones religiosas y mundanas cuyos beneficios redundan en los propios fundadores Lope Sánchez de Triana y Catalina de Medina y, en última instancia, en el colectivo social en el que éste se incardina. Con la erección y dotación del convento se cumplen estos cometidos: la satisfacción de un impulso religioso particular; la manifestación externa del poder y fuerza del linaje; la privatización de un colectivo dedicado a la mediación espiritual del linaje y a la intersección por sus individuos muertos y vivos y, en fin, la creación de un marco vivencial que sirva de refugio a las mujeres de la familia, teniendo en cuenta el mecanismo restrictivo que supone la dote, para el acceso a los conventos para las mujeres de su clase social ${ }^{9}$.

El convento fue una manera de colocar a las mujeres excedentarias del linaje, puesto que la concertación de matrimonios acordes con el status de pertenencia pasaba por la exigencia de la dote y ésta era superior en cuantía a la que se pedía a las monjas por la toma de hábitos ${ }^{10}$. En abierta conexión con las estrategias patrimoniales de la familia, la opción conventual era la salida moralmente más adecuada para aquellas jóvenes cuyos padres no se podían permitir cargar la herencia del mayorazgo por no ser ésta muy cuantiosa o ser excesivo el número de hijas a casar. Por todo ello los hombres y las propias mujeres de los grupos privilegiados se involucraron en los procesos de creación de la infraestructura conventual en provecho de sus propios linajes y en beneficio también del grupo social.

La integración conventual de mujeres emparentadas por vínculos de sangre $y$ el hecho de que toda la comunidad de monjas, parientas o no entre sí, se amalgame en un soporte de relaciones familiares, esta vez de origen espiritual (parentesco artificial), constituyen dos factores en interrelación que explican cómo los conventos actuaron como un medio ins-

9 Muñoz Fernández, op. cit.

10 El rey Felipe II había actualizado la cuantía de las dotes de los conventos femeninos, elevándola de 450 a 550 ducados, para adecuarlas a la desvalorización del dinero monetario ante la persistencia de precios altos. En cumplimiento con dicha disposición nuestros fundadores revocan la primera escritura para subir la cuantía a los 550 ducados estipuiados por la real cédula y además se especifica que sea "al contado", si bien se permitía dar en censo, uno o dos a lo sumo, mas sobre bienes o hipotecas seguras y fiables para "conservación y perpetuidad del dicho monasterio". 
titucional cohesionador de élites urbanas. En el caso del convento de la Concepción, la vinculación resulta aún más evidente ya que miembros de la familia por línea masculina y femenina se vinculaban a posteriori al patronazgo. En efecto, los fundadores muestran expresamente su deseo de que les sucedan en el patronato las personas elegidas, por el orden señalado y sus hijos descendientes de legítimo matrimonio, sin importar razón de sexo. Instituyen, pues, patronatos que detentarían miembros de su linaje en ramas colaterales; mas, acabada la línea y descendencia designada, es voluntad del matrimonio fundador.

«que suceda en el dicho nuestro patronazgo la abadesa del dicho monasterio y una capellana más antigua de la línea de mí el dicho doctor Triana y otra más antigua de la línea de la mi dicha dona Catalina" ${ }^{11}$.

A lo señalado se añade el derecho de reservación - que subrogan los fundadores en sus personas y en las de sus sucesores a perpetuidadde nombrar seis capellanas atres nombradas en nuestros días y las tres después de nosotros muertos... las cuales han de ser admitidas en el dicho monasterio sin que tengan obligación de pagar cosa alguna con su dote». El sustento material de las designadas habría de correr por cuenta del patrono, a excepción del año de noviciado en que las elegidas se obligaban a sufragar la cantidad de 24 ducados y 12 fanegas de trigo en concepto de pensión alimenticia. La escritura es más explícita aún al poner como exigencia moral la buena formación cristiana de las capellanas y de sus progenitores que han de ser ubuenos cristianos de conocida virtud y recogimiento". La influencia de la reforma tridentina y la obsesión por la garantía de la ortodoxia religiosa quedan patentes en la disposición duodécima de la escritura de fundación donde se declara que, si cualquiera de los patronos sucesores designados por los fundadores originales incurriese en delito de herejía o lesa majestad, se les aplicase, además de las penas de confiscación que el derecho preve a tal efecto, la pena de privación de todos los beneficios inherentes y, en consecuencia, la exclusión del patronazgo

"Salvo en caso que el delito sea de herejía que, en tal caso, queremos que toda aquella línea y descendencia en infinito quede excluida del dicho patronazgo ${ }^{12}$.

11 Cláusula número 11 de la Escritura de Fundación del Convento de la Concepción de Mérida (Badajoz). AHN Clero. Libro 994, f. ${ }^{\circ} 6 \mathrm{v}-7$.

${ }^{12}$ Escritura de fundación...AHN Clero Libro 994, f. 7. 
Condición sine qua non para las elecciones de los capellanes del Convento de la Concepción es que perteneciesen al linaje fundador dentro del cuarto grado. El nombramiento de capellán mayor se lo reserva el fundador en la persona de un sobrino carnal, el licenciado Juan Mexía "por concurrir en su persona las partes y requisitos de nuestra fundación". Se acrecienta dicha capellanía con una renta adicional perpetua de 20 ducados con carga de dos misas anuales en las solemnidades de los santos Lope y Catalina, cuyos nombres detentan los fundadores originales. El derecho de elección del capellán mayor lo ejercerá el fundador alternativamente con su esposa y cofundadora, doña Catalina de Medina, pero para este cargo se muestra, quizá como para ningún otro, una marcada preferencia por miembros del linaje propio con sólida formación intelectual, con preferencia sacerdotes graduados en cánones, leyes o teología. No obstante lo dicho, se permite a los patroneros adjudicar, una de cada tres prebendas por capellanías, a personas que no guardasen ningún grado de parentesco con el linaje fundador, aunque, asimismo se insiste en la obligación de proveer las dos primeras a varones o hembras pertenecientes al linaje, dentro de un cuarto grado de parentesco, siempre que los hubiere naturalmente.

\section{LA FUNDACIÓN COMO OBRA PÍA}

La sociedad de finales del sigloxvi se concebía en función de los valores religiosos. La vida de todo individuo estaba tutelada por la Iglesia desde el nacimiento hasta la muerte. Las ceremonias que rodeaban el tránsito a la otra vida estaban impregnadas de sentido religioso y controladas por los poderes eclesiales. La lectura de los testamentos de la época es una de las mejores fuentes para el conocimiento de las mentalidades, todos ellos comienzan con una invocación religiosa, expresan su fe, su esperanza en la misericordia divina y tratan de merecerla por medio de la caridad.

Una manera alternativa de ejercer esa caridad adoptaba la forma de fundaciones pías. La facilidad de fundación es la causa de que las instituciones se multipliquen, ya con carácter religioso (beneficios) o de instrucción (seminarios) o de beneficencia (instituciones para pobres, refugios de ancianos, hospicios de niños abandonados) hasta el punto de que los particulares pueden hacer libremente fundaciones.

Una sociedad proclive a la piedad y al fervor religiosos, promovidos, a su vez, por el aliciente y espíritu tridentino que tanto arraigó en la sociedad española cuyas capas dirigentes se interesaron por dotar a este tipo de fundaciones con un doble objetivo: emplear sus recursos eco- 
nómicos en fines que levantaban una ola de honor y respetabilidad y 'servirse de estos recursos como medio personal de salvación de su alma' ${ }^{13}$. Se trata, en definitiva, de realizar obras piadosas en las que la persona del patrono destaque por sus méritos y virtudes, dedicándole gran parte de los beneficios espirituales que vengan de la vida religiosa practicada en dicha institución.

Y precisamente de esta relación surge la mayor influencia social del monasterio, constituida por una paralelización recíproca entre las vocaciones religiosas y los donantes. Éstos quedan facultados para hacer una fundación a cambio de abtener del monasterio asilo sagrado de estancia, enterramiento o misas, oitodos los beneficios a la vez. A cambio se obliga a otorgar al convento ưha fundación en bienes, generalmente en forma de juro de heredad y tràs la entrega de dichos bienes, bien en dinero o en especie, se materializa una firme vinculación del donante.

Las donaciones de los fieles - nobles o hidalgos la mayoría de las ocasiones-cada vez más frecuentes para los fines de caridad hicieron que en el seno de la comunidad o junto a él surgieran, poco a poco numerosos ejemplos de las llamadas causas piae; es decir, instituciones constituidas por masas patrimoniales que los fundadores destinan a alguna obra de misericordia, en nuestro caso la fundación de un convento ${ }^{14}$.

El convento de la Concepción de Mérida es claro ejemplo de fundación pía no autónoma que en el Derecho Canónico se concibe como 'los bienes temporales, dados de cualquier modo a una persona jurídica pública con la carga de celebrar misas y cumplir otras funciones eclesiásticas determinadas con las rentas anuales, durante un largo período de tiempo que habrá de determinar el derecho particular' ${ }^{15}$. Atentos a este espíritu, el matrimonio formado por Lope Sánchez de Triana y Catalina de Medina, funda un monasterio de monjas de la Bienaventurada Santa Clara de la regular observancia ${ }^{16}$, sujeto a la obediencia del prior del convento de Santiago de Mérida, por tanto bajo el control del ordinario, tal y como venía siendo ya tradicionalmente. El convento habrá de tener - por ex-

13 Sánchez Hernández, M. L. El monasterio de la Encarnación de Madrid. Un modelo de vida religiosa en el siglo XVII. Madrid, Ed. Escurialenses, 1986, pág. 47.

${ }_{14}$ DEL GIUDICE, V Nociones de derecho Canónico. Pamplona 1955, pág. 254; citado en Badenes Gasset, R Las fundaciones de derecho Privado. Doctrina y textos legales. T.I. Barcelona, Librería Bosch, 1986, pág. 27.

15 VV.AA., Código de derecho canónico. Madrid, Biblioteca de Autores Cristianos, 1989. canon 1303, 1. 2.

16 Queda derogada en 1597 la regla de la primitiva comunidad, pues la fundación original, fechada en 1592, se hizo bajo el instituto de la orden tercera de San Francisco. Ver Apéndice n. 3 . 
preso deseo de sus fundadores- por advocación el Santísimo Nombre de Jesús, referencia espiritual de todas las acciones de las monjas de la comunidad.

\section{1. «Pro ecclesia» et «Pro anima»}

Los fundadores de la Concepción de Mérida no son una excepción en el sentir de la época. Así pues, en el preámbulo mismo de la escritura de dotación aparece de manera explícita el natural deseo de responder con una obra pía a todas las gracias y favores obtenidos por la infinita gracia divina

"empleando las potencias del ánima en su servicio y el caudal de sus talentos en aprovechamiento de sus prójimos, disponiendo en todo los caminos de Dios para le venir a gozar... reagradeciendo esta merced estamos obligados a le servir con todas las fuerzas y caudal considerando estos y otros grandes infinitas mercedes y beneficios que de la mano de Dios sin merecimiento nuestro hemos recibido y cada dia recibimos" ${ }^{17}$.

En consecuencia, para gloria del Altísimo y provecho de sus almas otorgan escritura de fundación y dotación de un convento de monjas de la Orden de Santa Clara, de la regular observancia, en la ciudad de Mérida. El día 15 de agosto de 1592, en Madrid, ante escribano público, se fecha una primera escritura que será confirmada posteriormente por el soberano Felipe II, el 2 de noviembre y por el capítulo general de la Orden de Santiago, celebrado en Madrid el año $1600^{18}$.

Se trata, pues, de una donación inter vivos que responde, según la aspiración espiritual del donante, al tipo de donaciones religiosas pro ecclesia - al tener como objetivo primordial el alojamiento y supervivencia material de una comunidad religiosa con la responsabilidad moral subsiguiente- pero también al tipo pro anima según y como se deriva de las cargas y obligaciones anexas a la dotación económica y que se contienen en la escritura de fundación.

17 Fundación del convento de la Concepción... AHN Clero. Libro 994, f. ${ }^{\circ} 6 \mathrm{v}$.

1 Véase Apéndice número 3. 


\subsection{Contrato sinalagmático. "Do ut facias"}

Por su parte la comunidad acepta la fundación y la recibe con todas las cargas y obligaciones impuestas ${ }^{19}$. La fundación legítimamente aceptada reviste carácter de contrato sinalagmático o bilateral, do ut facias, (doy para que hagas lo contratado) y así se otorga a las dos partes por justicia conmutativa ${ }^{20}$.

Así pues, a cambio de la dotación económica del monasterio y capilla, los patronos se reservan en sus personas y en las de sus sucesores el derecho a recibir «todas las honras, derechos, gracias y libertades que los sacros cánones conceden a los que fundan y dotan semejantes monasterios y obras pías".

Al ser una fundación inter vivos, los fundadores estipulan una serie de exigencias, ciertamente gravosas, en recompensa de los aprovechamientos temporales que distribuyen en vida a la comunidad religiosa; entre otras destacan las siguientes:

1. Obligación expresa de celebrar dos veces al año un novenario en honor de Nuestra Señora y dos misas más de solemnidad en las festividades de San Francisco y San Antonio de Padua, respectivamente.

2. Misas de ordinario, por las cuales los cofundadores ofrecen un estipendio de 100 ducados anuales, "contando a razón de seis reales de limosna cada misa». Se añade taxativamente

«y declaramos que el dicho número de misas se han de decir por cada capellán, de manera que por espacio de dos años, cada uno de nuestros capellanes haya dicho por nosotros todas las misas y oficios propios de los santos de que reza la Iglesia en el breviario y misal romano ${ }^{21}$.

3. Siendo la comunidad competente por formar parte de la misma monjas "de velo y coro", se compromete a decir todos los días del año

19 El Código de derecho Canónico... op. cit. en su canon 1304, 1. reza Ut fundatio a persona iuridica valida acceptari possit, requiritur licentia Ordinarii in scriptis data...Es decir, para que una persona jurídica pueda aceptar válidamente una fundación, se requiere licencia escrita del Ordinario, esto es, del Romano Pontífice, los Obispos diocesanos y todos aquellos que, aun interinamente, han sido nombrados para regir una Iglesia particular y también quienes en ellas tiene potestad ejecutiva ordinaria, los vicarios generales y episcopales. Dicha licencia no se dará sin haber comprobado legítimamente que la persona jurídica puede cumplir tanto la nueva carga como las anteriormente aceptadas; y deben cuidar sobre todo de que las rentas cubran totalmente las cargas anejas, según los usos del lugar o de la región.

${ }^{20}$ Ferreres, J.B. Instituciones canónicas con arreglo al código de Pío X.T. II, tit. XXX. "De las Fundaciones Pias», canon 1544.2. Barcelona, Ed. Pontificia, 1934.

21 Fundación del convento de la Concepción... AHN Clero. Libro 994, f. ${ }^{\circ} 11 \mathrm{v}$. 
una misa mayor cantada. En las fiestas conmemorativas de la ciudad de Mérida, las misas serán concelebradas por los capellanes y ministros del ordinario.

4. Así mismo, las monjas se obligan a cantar un responso todos los viernes del año y al rezo, cada sábado, de la letanía del Nombre de Jesús y del Santísimo Sacramento, así como un rosario en Pascua de Navidad, de Resurrección y Pentecostés, por el alma de los fundadores, vivos o difuntos.

\section{DE LA CONSTITUCIÓN Y GOBIERNO}

1. El matrimonio formado por Lope Sánchez de Triana y Catalina de Medina concibió un proyecto multifuncional, convento de acogida a mujeres del linaje que manifestasen su deseo de ingresar en la Orden de Santa Clara, iglesia, capellanías y lugar de reposo para los fundadores tras el momento de la muerte. Los fundadores dispusieron para la localización del convento, iglesia y capilla sus casas principales, adquiridas a este fin a Hernando de Vera y Vargas, vecino de la ciudad de Mérida, colindantes, pues, con las casas del mayorazgo de los Veras. El terreno inicial se engrandecería con adquisiciones sucesivas de otras propiedades anejas.

Las inversiones por mejoras realizadas en el inmueble ascendieron a un total de 9.000 ducados, dato que nos proporciona por sí solo una idea aproximada de lo elevado del status económico del matrimonio fundador, pero que es, al mismo tiempo, razón que justifica la prohibición expresa de que el convento mude de lugar, bajo la pérdida de todos los beneficios otorgados:

"queremos que perpetuamente sirva para este efecto y que por ninguna causa que sea o ser pueda se mueva, trasfiera ni pase el dicho convento de la dicha casa, aunque sea con color de mejoría o de otras cualesquier consideraciones, ni se pueda vender, ni enajenar por ningún caso, aunque sea con licencia de Su Santidad, ni de Su Magestad y por el mismo caso que lo tal se intente... pierdan ipso facto sus oficios y beneficios sin otra declaración alguna y queden inhábiles e incapaces de los poder tener y usar, ni ser nombrados ni elegidos para ellos" ${ }^{22}$.

22 Escritura de Fundación del convento de la Concepción... AHN Clero. Libro 994, cláusula n. 2 , to. 3-3v. 
Esta renuncia a los bienes propios en beneficio del monasterio lleva implícita la siguiente exigencia, esto es, el derecho de habitación de por vida en unos aposentos destinados a tal fin en las casas mencionadas y que los fundadores eligen por haber servido de morada al rey Felipe II en 1580 cuando se dirigía camino de Portugal y en el transcurso, pues, de las operaciones militares con motivo de la conquista de aquel reino.

2. Los fundadores asignan, asimismo, una renta perpetua al convento en bienes de propios, en forma de censo al quitar ${ }^{23}$, por valor de 202.585 maravedís, situados en propios, rentas y dehesas de la ciudad al 16 por 100 , sobre un capital principal valorado en 3.161 .342 maravedís, más 18 fanegas de trigo anuales de renta y censo perpetuo. Esta renta, correspondiente a la primera escritura de dotación, será, no obstante incrementada, diez años más tarde, por una segunda escritura, hasta un valor de 503.044 maravedís y 18 fanegas de trigo anuales.

3. Se instituyen además ocho capellanías, 7 de ellas aplicadas a seis capellanes y un sacristán y el capital beneficiado por la octava se habría de utilizar en los gastos de la fábrica de la iglesia y capilla. La dotación económica de cada una de las capellanías se elevaría a la cifra de 100 ducados anuales, situados en juros sobre alcabalas, dehesas y casas de la ciudad de Mérida y diversos bienes y personas vecinos de la misma, a contar desde el día primero de abril de 1601 en adelante aaunque en el dicho convento no hayan entrado monjas" ${ }^{24}$.

4. Sobre la formación intelectual de las monjas, las exigencias fundacionales son muy selectivas

"queremos y es nuestra voluntad que las capellanas que se hubieren de nombrar y admitir en el dicho monasterio sean hábiles y suficientes para ser monjas y no simples mentecatas" ${ }^{25}$.

Y esta razón es de tal peso que se antepone a la exigencia de consanguinidad y pertenencia al linaje. $Y$ así se especifica como pauta de conducta en el futuro a los sucesores en el patronato

${ }^{23}$ Se impone como condición al deudor que cuando hubiere de redimir el censo lo comunique al convento con dos meses de antelación para darle la oportunidad de volver a encontrar nuevo censatario y no sufrir menoscabo en la hacienda monástica.

${ }^{24}$ Capellania es una entidad jurídica que consiste: a) en el derecho a percibir los frutos de determinados bienes, b) y en una obligación u oficio espiritual que suele reducirse a celebrar cierto número de misas a intención del fundador. En este caso se trata de capellanias laicales al no quedar espiritualizados sus bienes y no constituir, pues, verdadero beneficio. Se erige sin autorización del Obispo, aunque sea este quien haya de conferirla. FerRERES, op. cit., pág. 175, n. ${ }^{\circ} 409$.

${ }_{25}$ Escritura de fundación del convento de la Concepción... AHN Clero. Libro 994, f. ${ }^{\circ} 8$. 
«que sepan leer, contar, escribir y cantar canto llano y algo de canto de órgano, corneta, flauta, baxón o arpa, y si alguna de nuestras monjas fuese diestra en canto de órgano y supiese tocar algún instrumento músico... sea admitida como capellana nuestra y preferida a las deudas más cercanas para que así Nuestro Señor sea mejor servido en su coro" ${ }^{26}$.

El conocimiento musical es por sí mismo criterio de selección, pues en una sociedad donde la tasa de alfabetización rondaba el 10 por 100 , la exigencia del dominio musical suponía por añadidura el perfecto conocimiento del latín, fundamental para el seguimiento del culto y de los sagrados cánones de la liturgia romana; cuanto más las monjas destinadas al coro, para quienes era imprescindible a la hora de interpretar la liturgia cantada. Bien es verdad que la obligatoriedad se aplica a los cuatro primeros supuestos, es decir, lo concerniente a la lectura, escritura, conocimiento básico de las matemáticas y canto llano.

Y si es importante el grado de formación intelectual, mayor es si cabe el grado de exigencia espiritual. El punto de partida es axiomático, indiscutible, se desea velar por la seguridad en la pureza de las costumbres de la colectividad de monjas que constituye la comunidad religiosa. Consecuentemente, es motivo de exclusión automática la pérdida de la virginidad por trato deshonesto e ilícito, no sólo de la autora del delito, sino también de cualquier persona que, habiendo estado a su servicio en tiempo pasado, hubiese encubierto tales actos vergonzosos

"Así y para que no puedan pretender ignorancia, declaramos que esta nuestra claúsula sea leida a las dichas capellanas al tiempo de entrada y profesión en el monasterio y destas dos calidades se haga información a las demás" ${ }^{27}$.

La reforma tridentina implicaba, sobre todo, la aceptación de la clausura estricta. El Concilio se ocupó de perfilar con exactitud el más rigorista concepto de la clausura que pudo encontrar; se trataba de un encierro absoluto: nadie dentro del claustro y ninguna monja fuera de él. Acordes con el espíritu mencionado, los fundadores del convento de la Concepción de Mérida prohiben taxativamente cualquier trato o conversación de los capellanes con las religiosas en sus locutorios a fin de no dar motivo de escándalo alguno. Tampoco se consentiria ningún trato deshonesto con otra mujer extramuros del convento, en caso contrario entrañaría la pér-

26 Ibidem.

${ }^{27}$ Escritura de Fundación del convento de la Concepción... AHN Clero. Libro 994, f. 9. 
dida de todo beneficio anejo a la prebenda por capellanía y la exclusión de la casa y capilla.

Así la labor de Trento, apoyada por los superiores masculinos de las diversas órdenes posibilitó que la clausura fuera respetada sin muchas dificultades y que la normalidad en la vida regular fuera la nota más característica en todas las comunidades religiosas.

5. Respecto del ejercicio del culto divino, al disponerse explícitamente que dependa de "buenos ministros", se autoriza a un capellán a asistir a la Universidad, a fin de conseguir una correcta preparación en artes, teología y leyes. Se le permitiría gozar del beneficio íntegro de la prebenda mientras durase el tiempo de estudio por lo que su plaza en el convento sería detentada de forma interina por un clérigo de misa «de conocida virtud" y con licencia para la administración de sacramentos. Con esta disposición se satisface la atención espiritual de las religiosas y se garantiza el cumplimiento de la carga de misas en beneficio de los fundadores ${ }^{28}$.

En 1602, como queda dicho, se modificó la escritura original de 1592 , con aprobación del prior de la provincia de León y tras haber obtenido licencia real para verificar la nueva fundación. Su Majestad el rey Felipe III concede el otorgamiento de la nueva escritura de Lope Sánchez Triana y Catalina de Medina mas con algunas condiciones entre las que cabe destacar la subordinación, por parte de la abadesa y monjas del convento, a la administración perpetua por los maestres de la Orden de Santiago; la admisión de la visita a los priores de San Marcos de León o a las autoridades que ellos designaren y la competencia del prior de la provincia de León o miembros del Consejo de Órdenes en cualquier pleito causado por el convento en sus personas, bienes o posesiones.

\section{CONCLUSIÓN}

Al comenzar el siglo XVII las clarisas se hallaban en un momento cenital de su historia. Seguian siendo, con toda seguridad, mayoritarias en toda la Península. La fiebre fundacional continuó por lo menos hasta 1630 aproximadamente hasta que se significaron los primeros síntomas de la crisis. Recibieron tanto el apoyo de la monarquía, como de diversas casas nobiliarias e incluso de grupos de oligarquías tanto urbanas como rurales,

${ }^{28}$ Se dota a tal efecto una cifra de 500 reales para sufragar un total de 125 misas, a razón de 4 reales de limosna cada una. 
como en el caso que acabamos de considerar. La espiritualidad clariana y el respeto a la regla revistió a la orden con un prestigio mayor que el alcanzado en épocas anteriores. La reforma continuó en el reinado de Felipe III con dos directrices fundamentales: la puesta en práctica de todos los preceptos tridentinos, especialmente el de la clausura y más adelante la ayuda mediante mercedes y privilegios a distintos conventos que verán, cernirse sobre ellos los efectos de la crisis.

\section{APÉNDICE $n .^{\circ} 1$}

\section{CONFIRMACIÓN REAL DE LA FUNDACIÓN DEL CONVENTO DE LA CONCEPCIÓN DE MÉRIDA. 1592}

Primera Escritura de Fundación del Convento de la Concepción de Mérida (Badajoz). AHN Clero. Libro 994, $f .^{\circ} 1$.

Don Felipe por la gracia de Dios, rey de Castilla, de León, de Aragón de las dos Sicilias, de Jerusalem, de Portugal, de Navarra, de Granada, de Toledo, de Valencia, de Galicia, de Mallorca, de Sevilla, de Cerdeña, de Córdova, de Córcega, de Murcia, de Jaén, de los Algarves, de Alxeciras, de Xibraltar, de las islas de Canaria, de las Indias Orientales y Occidentales, islas y Tierra Firme del mar océano, Archiduque de Austria, duque de Borgona, de Brabante y Milán, conde de Flandes y del Tirol y de Barcelona, señor de Vlzcaya y de Molina, administrador perpetuo de la Orden y Caballería de Santiago, por autoridad apostólica.

Por cuanto por vos el doctor Triana, vecino de la Ciudad de Mérida, me fue hecha relazion que vos y doña Catalina de Medina, vuetra muger, hicisteis y fundasteis en esa dicha ciudad un monasterio de monjas de la Orden de Santa Clara, advocación del Nombre de Jesús y le anexasteis renta suficiente, en mi Consejo de las Ordenes se os dio liçencia para hacer la dicha fundación con que truxesedes al confirmar el primer capítulo en la villa de Madrid; presentásteis en él la dicha fundación y me suplicasteis la mandase ver, aprobar y confirmar para que fuese guardada, cumplida y ejecutada...

... Por ende, con acuerdo de los de mi Consejo de Ordenes, tuve por bien de dar esta mi carta la cual, sin perjuicio de tercero confirmo y apruebo la escritura de dotación y fundación del dicho monasterio y doy licencia y facultad a vos el dicho Lope Sánchez de Triana para que conforme al tenor de la dicha dotación en esa ciudad de Mérida podáis fundar y fundéis el dicho monasterio de monjas de la penitencia de la tercera orden de San Francisco, como se declara en le dicha escritura de dotación y no embargante el establecimiento que dispone que sin licencia del Capítulo General de la dicha Orden no se funde monasterio en los pueblos de ella, con lo cual, en cuanto a lo susodicho, por esta vez yo dispenso quedando en su fuerza y vigor para en lo demás adelante...

.. Mando a los priores, vicarios y curas de la dicha Orden, comendadores mayores y caballeros de ellas, a los visitadores de la Orden y al mi gobernador 0 juez de residencia que es o fuere de la dicha ciudad de Mérida y concejo de ella, que dejen $y$ consientan hacer $y$ fundar el dicho monasterio, sin que ello pongan 
ni consientan poner embargo o impedimento alguno so pena de la mi merced y de cien ducados de oro para obras pías con tanto que esta mi licencia y escritura de dotación se lleve a aprobar y confirmar al primer Capítulo General de la dicha Orden, se celebrase con apercibimiento que, si no lo hiciéredes, sea en sí mismo y de ningún valor y efecto de lo cual mandé dar y di esta mi carta firmada de mi mano y sellada con el sello de la dicha Orden, en el monasterio de la Estrella, a dos de noviembre de mil y quinientos y noventa y dos. Yo el Rey.

\section{APÉNDICE $n .^{\circ} 2$}

\section{LICENCIA PARA LA CONMUTACIÓN EN ORDEN DE SANTA CLARA. 1597}

Primera Escritura de Fundación del Convento de la Concepción de Mérida. AHN. Clero. Libro 994, f. 18.

El rey. Por cuanto por parte del doctor Triana, vecino de la ciudad de Mérida, me ha sido hecha la relación que habiendo fundado con licencia mía un monasterio de monjas de la orden tercera de la penitencia, el año pasado de noventa y dos y después por el de noventa y siete se había dado asimismo licencia para que se conmutase en la Orden de Santa Clara y que las monjas que entrasen diesen quinientos y cincuenta ducados y que trayendo a confirmar la dicha licencia al Capítulo general de la Orden de Santiago que últimamente mandé celebrar en la villa de Madrid el año pasado de mil seiscientos, se le había perdido. Atento a lo cual cesaba el efecto de la dicha licencia de que recibía mucho daño. Y para remedio de ello me suplicó le mandase dar otra cédula y licencia de los libros donde estaba asentada por perdida, como la mi merced fuese.

Lo cual, visto por los de mi Consejo de Ordenes y la dicha licencia asentada en los libros, mando que no embargante que el dicho monasterio habia de ser de monjas de la tercera Orden de San Francisco de la Penitencia, conforme a las dichas escrituras, haya de ser y sea de monjas de Santa Clara de la dicha Orden, debajo de cuya regla e instituto hayan de vivir y vivan y mando que ninguna monja pueda ser recibida en él sin que haya de llevar y lleve los dichos quinientos cincuenta ducados de dote. Lo cual quiero que así se haga y cumpla, no obstante lo contenido en las dichas escrituras de fundación porque así es mi voluntad.

Fecha en San Lorenzo el Real a diez y ocho de junio de mil y quinientos noventa y siete años. Yo el Rey. Yo Francisco González de Heredia, secretario del Rey nuestro señor la hice escribir por su mandado. 


\title{
APÉNDICE $n .^{\circ} 3$
}

\author{
CONFIRMACIÓN REAL DE LA LICENCIA DE FUNDACIÓN, UNA VEZ APROBADA \\ POR EL CAPITULO GENERAL. 1600
}

Primera escritura de Fundación del Convento de la Concepción de Mérida (Badajoz). AHN. Clero. Libro 994, f. ${ }^{\circ}$ 17-17v.

... Y así presentada la dicha escritura de dotación y fundación en el dicho Capitulo General, me suplicasteis la mandase confirmar para que fuese guardada, cumplida y ejecutada como la mi merced fuese y yo con acuerdo de los reverendos padres... que son los trece de la dicha Orden, túvelo por bien y por la presente sin perjuicio de tercero y de mis rentas reales y maestrales, confirmo y apruebo la dicha escritura de dotación y fundación que de suso va incorporada, fecha por el doctor Lope Sánchez de Triana y Catalina de Medina, su muger y mando que sea cumplida y ejecutada en todo y por todo según y como en ella se contiene y defiendo firmemente que ningunas personas no vayan ni pasen contra el tenor de la dicha escritura de donación y fundación so pena que si fuere fraile, le será demandado según Dios y Orden, y si fuese seglar y muera, en pena de la mi merced y diez mil maravedís para la mi cámara. De lo cual mandé dar y di esta mi carta, firmada de mi mano y sellada con el sello de la dicha Orden y del dicho Capítulo General.

Dada en San Lorenzo el real a diez y ocho dias del mes de octubre de mil y seiscientos años. Yo el Rey. 